\title{
Hydro-ecological modelling to establish sustainable extraction limits in unregulated catchments
}

\author{
$\underline{\text { K. Savadamuthu }}^{\text {a }}$, M. van der Wielen ${ }^{\text {, }}$ M.R. Alcorna and J. Vanlaarhoven ${ }^{a}$ \\ ${ }^{a}$ Department for Water, Government of South Australia. \\ ${ }^{b}$ South Australian Murray-Darling Basin Natural Resources Management Board. \\ kumar.savadamuthu@sa.gov.au,.mark.alcorn@sa.gov.au,Jason.vanlaarhoven@sa.gov.au, \\ mardi.vanderwielen@samdbnrm.sa.gov.au
}

\begin{abstract}
Statutory water allocation plans are an important tool for sustainable water resource management in South Australia. Water allocation plans need to achieve a balance between social, economic and environmental needs for water when establishing sustainable extraction limits. This paper outlines the hydrological and ecological modelling interface used in helping to develop the proposed sustainable extraction limits for the surface water resources of the Mt Lofty Ranges (MLR) region.

Two draft water allocation plans have been recently prepared, one for the eastern MLR and one for the western MLR. The catchments are ephemeral and largely unregulated, where the majority of surface water capture is via thousands of private farm dams. The larger catchments in the western MLR also include public water-supply reservoirs supplying Adelaide. A key challenge is to develop sustainable extraction limits and taking rules, which will practically apply to thousands of private dams in order to provide an environmentally appropriate water regime, as well as providing for social and economic water needs.
\end{abstract}

In developing the plans, key components that contributed to defining sustainable extraction limits included:

- Surface water resource capacity - Catchment modelling to estimate the total quantity of water available within the MLR region (daily and annual flow), with the impact of recent developments (farm dams, plantation forestry and watercourse extractions) accounted for.

- Environmental water requirements (EWR) - Representation of EWRs as a series of hydrological statistics, termed as 'EWR metrics'. An environmental target was set, based on the metrics, which was expected to have an acceptable level of risk of meeting the environmental objectives.

- Scenario modelling - Scenario modelling was used to estimate impacts of different management strategies on meeting the environmental target and consumptive demands across the MLR, including current conditions, variable demand, and taking rules that return low flows to the environment. The outcomes were used to assist identifying sustainable extraction limits that balance different water needs.

A suite of hydrological and ecological modelling tools were used, including:

- Water resource modelling platform (WaterCress) to represent the various water supply and demand components of the water-balance.

- Rainfall-runoff models within the modelling platform. Daily time-step partially distributed catchment models were calibrated for all the long-term gauged sub-catchments in the region. Rainfall-runoff relationships developed from these calibrated models were then used to simulate runoff from similar neighboring ungauged sub-catchments. Rainfall, slope, soil type and land cover parameters were used to extend the rainfall-runoff relationships to ungauged catchments.

- An analysis framework to link various components of the water balance and flow model outputs to EWR metrics. This enabled simulation of various demand scenarios and their impacts on the flow regime.

The above-mentioned suite of hydro-ecological modelling and analysis tools were then linked to derive the final sustainable extraction limits (SEL) for the entire MLR region.

Keywords: Water allocation planning, modelling, hydrology, hydrological modelling, hydro-ecological modelling, environmental water requirements, environmental water provisions, sustainable extraction limits, catchment water-balance, rainfall-runoff generation. 
Savadamuthu et al., Hydro-ecological modelling to establish sustainable extraction limits in unregulated catchments

\section{INTRODUCTION}

The demand on the water resources of the Mt Lofty Ranges (MLR) to the east and south of Adelaide has been gradually increasing, to meet needs such as irrigation, stock and rural domestic use, expansion of semiurban development, and water supply reservoirs servicing an increasing urban population. This increasing demand, combined with a highly variable rainfall and hence, runoff pattern has led to clear signs of the catchments' flow regime being altered. This alteration raises significant concerns on the security of supply for key current demands, including water-dependent ecosystems and consumptive demand.

Water resources in the MLR in South Australia are prescribed under the South Australia's Natural Resources Management Act 2004 (the Act). Two draft Water Allocation Plans were recently prepared, one for the eastern MLR (draft EMLR WAP) and one for the western MLR (draft WMLR WAP). With regards to environmental water requirements, the Act requires that the Plan must include an assessment of the quantity and quality of water needed by the ecosystems that depend on the water resource. It also requires a Plan to achieve a balance between social, economic and environmental needs for water when establishing sustainable extraction limits. The Plans are currently under different stages of public comments and ministerial approval.

This paper describes the hydrological and ecological modelling used in helping to develop the proposed sustainable extraction limits for the surface water resources of the eastern and western MLR Prescribed Water Resources Areas (PWRA).

\section{THE MT LOFTY RANGES PRESCRIBED WATER RESOURCES AREAS}

The MLR PWRAs include 72 catchments over approximately $5600 \mathrm{~km}^{2}$, draining 10,422 km of mostly seasonal watercourses. Catchments of the region straddle two drainage basins: the Western MLR catchments that drain into the Gulf of St Vincent west and south of Adelaide (including the Fleurieu region in the south); and the Eastern MLR catchments, part of the Murray-Darling Basin, which drain into the River Murray and Lake Alexandrina (Figure 1).

Rainfall in the region ranges from around $1200 \mathrm{~mm}$ on the central ridgeline of the ranges to less than $400 \mathrm{~mm}$ in the plains to the east and west. The watercourses are generally ephemeral and largely unregulated, although the larger catchments of the WMLR drain to public water-supply reservoirs located on the foot-hills. An estimated 20,000 private farm dams in the region have a total capacity of close to 55,000 ML (VanLaarhoven and van der Wielen, 2009).

Diversion, capture and use of catchment runoff through farm dams in the upper reaches of the catchments and diversion and extraction of stream flow from watercourses in the lower reaches is the predominant practice that provides water to the most of the demands apart from the water-supply reservoir demands.

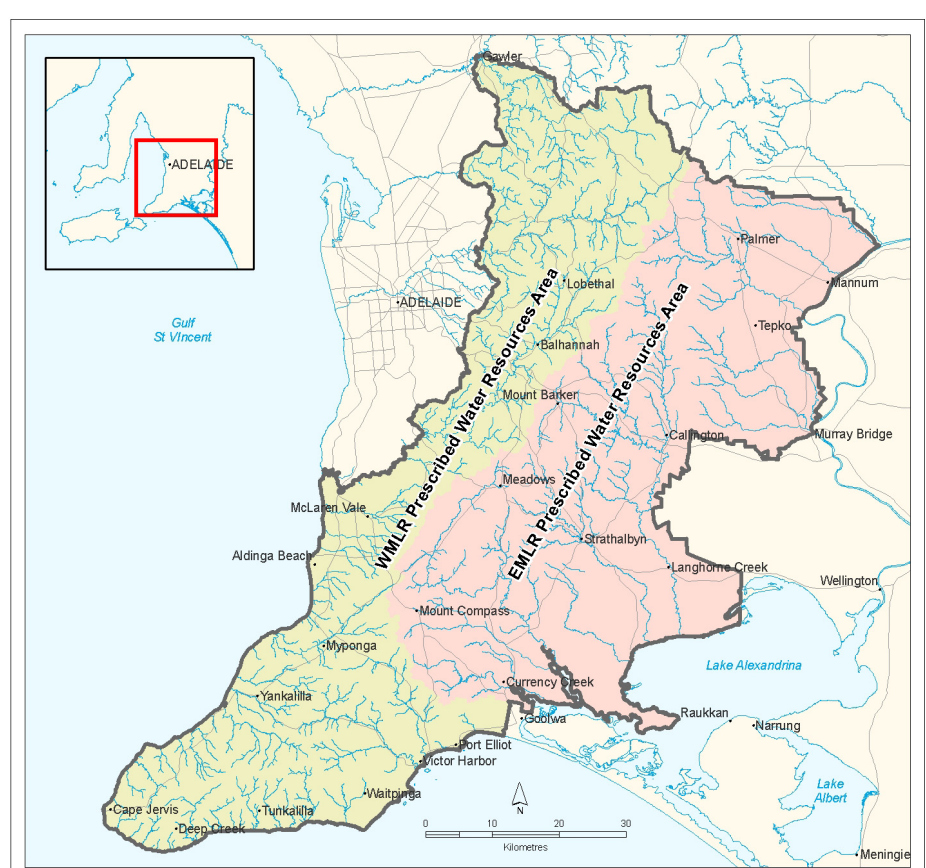

Figure 1. Mount Lofty Ranges Prescribed Region

\section{SUSTAINABLE EXTRACTION LIMITS}

\subsection{Overview}

Both draft Plans set out sustainable extraction limits, which are considered to be the maximum volume of water that can be extracted for consumptive use while providing for the environment. A simple schematic (Figure 2) is shown to provide an overview of the main components involved in the overall framework for establishing sustainable extraction limits for the region, including resource capacity (total water availability) and environmental water provisions (provisions made for the environment after considering acceptable levels of risk to environmental requirements and current consumptive demands). The surface water modelling and 
Savadamuthu et al., Hydro-ecological modelling to establish sustainable extraction limits in unregulated catchments

ecological analysis used in this process are outlined in the next sections. Consideration of social and economic issues are not discussed in this paper.

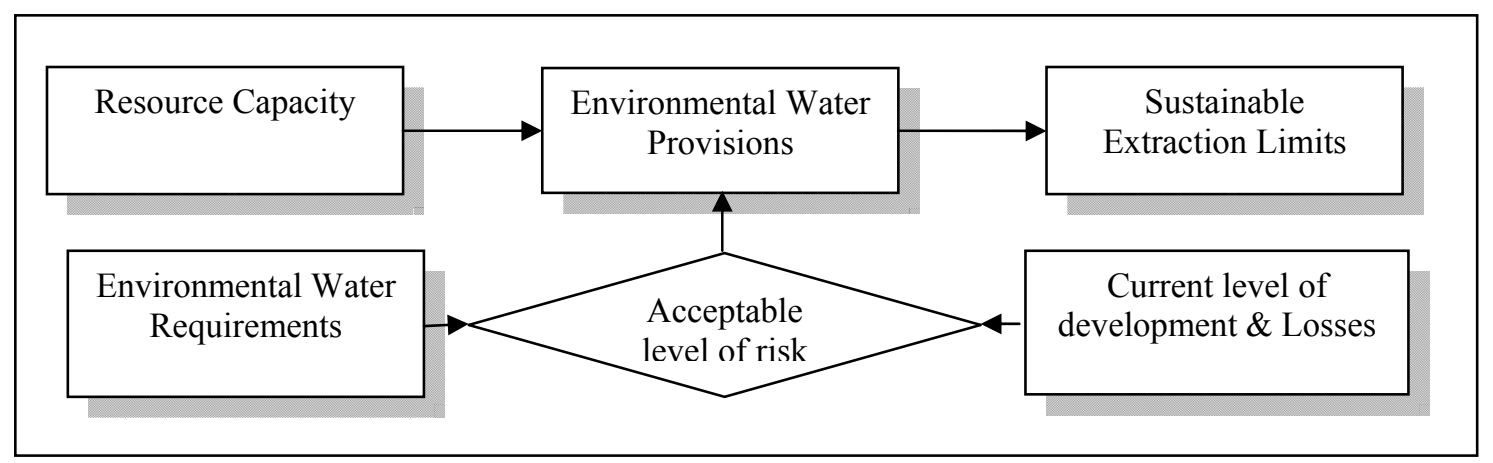

Figure 2. Sustainable extraction limit establishment framework

\subsection{Resource Capacity}

Resource capacity, in simple terms, is the total volume of water that would be available within a catchment if farms dams and plantation forestry were not present. In case of the draft EMLR WAP, the definition also includes "if watercourse extractions were not present". Hence, whenever reference to farm dams is made in this paper, it also includes watercourse extractions for the EMLR.

In modeling terms, this involves modeling to account for the impacts of farm dams and plantation forestry on runoff. This was undertaken in two stages, accounting for farm dams first and then for plantation forestry. While one consistent approach was taken across the region to account for the impacts of plantation forestry, a slightly different approach was used for accounting for the impacts of farm dams in the Fleurieu region compared with the rest of the MLR. The steps involved in estimating the resource capacities using the two different approaches is illustrated in figure 3 , and the main components involved in the modeling exercise are discussed in the following sections.

\subsubsection{Model construction and calibration}

Catchment rainfall-runoff models were constructed and calibrated to daily stream flow records for all gauged sub-catchments using the WaterCress platform (Cresswell, 2010) to represent the current scenario (S1 in Figure 4). WaterCress is a node-link water balance modeling platform and includes:

- runoff generation models including AWBM, SimHyd, Sacramento and WC1. AWBM and WC1 models were used for the different sub-catchments in the region.

- supply, demand, loss and routing nodes. Rural catchment, urban catchment, farm dam, watercourse demand and routing were the nodes used in this case.

- calibration tools, including optimization routines for calibration and tools (tables, charts and statistics) for comparing the calibration results. All models, in this case, for the were calibrated to daily stream flow records and verified used hydrographs (daily, monthly and annual), daily flow exceedance curves and statistics ( $\mathrm{R}$ and coefficient of efficiency).

Detailed description on (i) the various types of nodes used in the models, (ii) the calibration and validation process involved and (iii) the assumptions and limitation of the modeling exercise undertaken are provided in the published reports for the individual catchments, which can be accessed from http://www.waterconnect.sa.gov.au .

Models were then constructed for the ungauged sub-catchments in the same way as for gauged subcatchments, with the only difference being in model calibration. Since these sub-catchments are ungauged, runoff from these catchments were simulated using catchment parameters from the calibrated models of similar gauged sub-catchments in the region.

\subsubsection{Scenario modeling}

The farm dams incorporated in the models were removed and flows generated to obtain what is termed as "No-dams" flow (Scenario S2 in Figure 4). Relationships between annual rainfall and no-dams annual flow for all the sub-catchments were developed using the Tanh function (Grayson et al., 1996). 
Savadamuthu et al., Hydro-ecological modelling to establish sustainable extraction limits in unregulated catchments

Surface water, in the Plans, is proposed to be managed at a Surface Water Management Zone (SWMZ) scale. SWMZs are generally smaller catchment areas within sub-catchments and defined on the basis of geomorphological-ecological stream reach types. The no-dams annual flow for the SWMZs were derived from the corresponding sub-catchment Tanh curves and the annual rainfall averaged across the SWMZ.

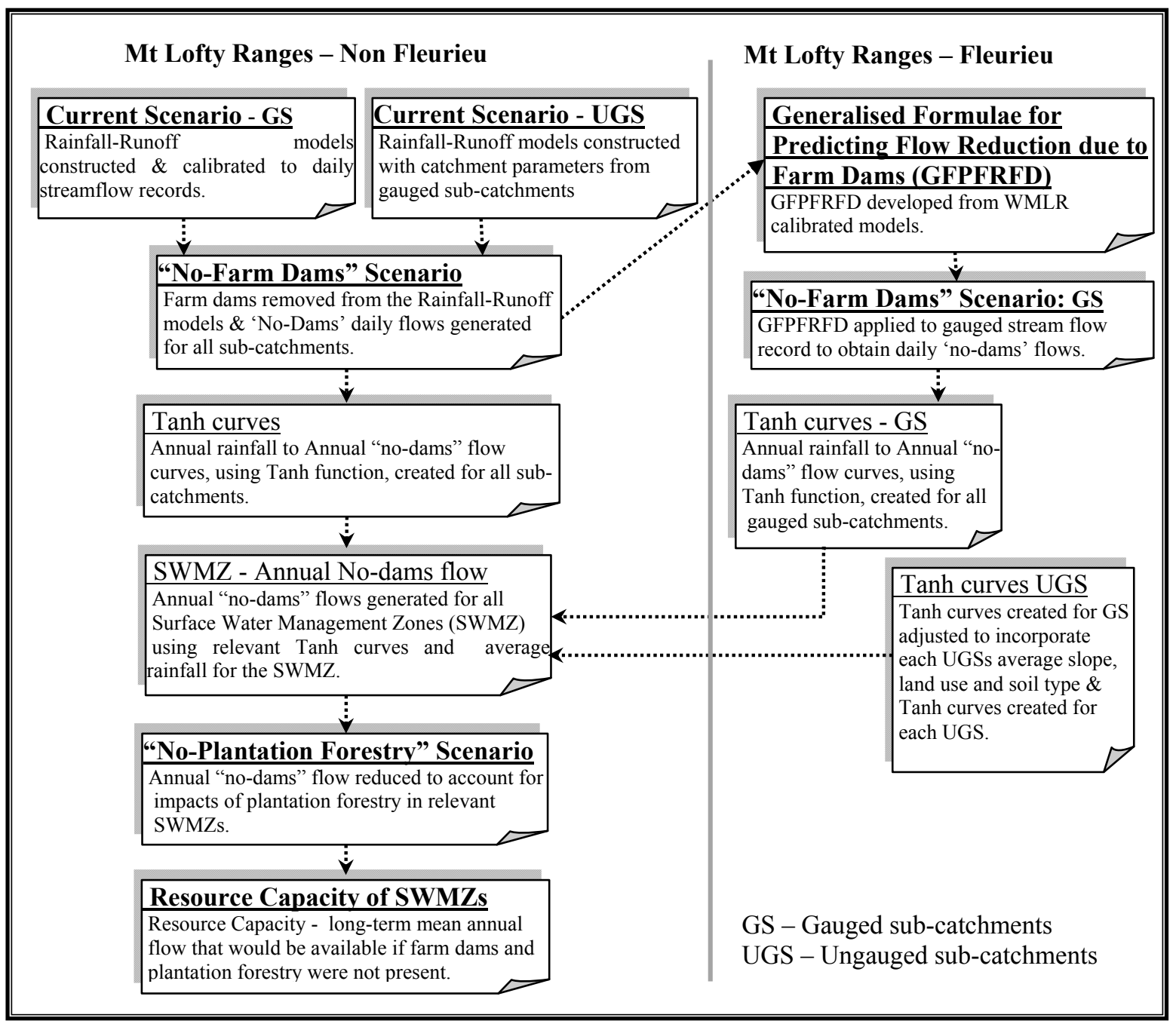

Figure 3. Resource capacity estimation process

In areas with plantation forestry, the no-dams annual flow was further adjusted to account for the impact of plantation forestry. The accounting was undertaken on the basis that plantation forests can be assumed to reduce runoff by $85 \%$ (SA Government, 2009). The final result (ie. the resource capacity for each SWMZ) is the runoff estimated from that zone if farm dams and plantation forestry were not present in that zone.

A full description of the modeling and analysis undertaken to estimate surface water resource capacities for the PWRAs of the MLR is provided in the Department for Water's published Technical Notes 2010/04, 2010/05 and 2011/02 and can be accessed from http://www.waterconnect.sa.gov.au.

\subsection{Environmental Water Requirements}

Environmental water requirements (EWRs) have been defined as 'the water regime needed to sustain the ecological values of ecosystems, including their processes and biological biodiversity, at a low level of risk' (Government of South Australia, 2006). The EWRs of water-dependent flora and fauna inhabiting the watercourses and associated habitats in the eastern and western MLR have been determined by an expert panel, based on knowledge of local ecology, hydrology and geomorphology (VanLaarhoven and van der Wielen, 2009).

The 'natural flow paradigm' (Poff et al, 1997), which considers that water-dependent ecosystems have evolved in response to the flow regime that they experience, was adopted as a guiding principle. It is well 
Savadamuthu et al., Hydro-ecological modelling to establish sustainable extraction limits in unregulated catchments

established that changes to the flow regime can lead to changes in the structure and function of the dependent ecosystem.

\subsubsection{Scenario modeling - current state of EWRs}

The EWRs defined in section 3.3 were represented as measurable hydrologic 'metrics' that correspond to key, ecologically relevant parts of the flow regime including flow season, frequency, duration and magnitude (e.g. "duration of zero flow events in the Low Flow Season" is a metric). Limits were set for each metric in terms of how far it could deviate from its value under 'natural' conditions (no-dams flow) while still maintaining the ecological process supported by that flow component at low risk. A metric that remains within these limits is considered to 'pass' while a metric that exceeds these limits is considered to 'fail' to provide an adequate environmental water requirement.

Comparison of ecological monitoring data with the percentage of metrics passed at a site showed a good correlation between increasing ecological condition and increasing percentage of metrics passed. Meeting the EWRs at a site was considered to equate to passing all of the metrics at that site.

Assessment of whether environmental water requirements are currently being met across the MLR was undertaken by simulating daily flows at 135 nodes of the models calibrated for the gauged sub-catchments across the region for scenarios S1 (current) and S2 (no-dams) (figure 4). Comparison of flows from the two scenarios indicated that, of the 135 sites tested, only two sites passed all metrics under current conditions, and $50 \%$ of sites passed less than $75 \%$ of the metrics. Metrics associated with low flows had very high failure rates in each of the flow seasons; larger bankfull flows were only marginally impacted. Fresh flows (shorterterm small increases in flow that remain in the channel) fell between these in the proportion of metrics met (VanLaarhoven and van der Wielen 2009). This analysis, together with monitoring data showing poor or declining environmental condition in parts of the MLR (e.g. Hammer et al 2009), shows that environmental water requirements are not currently being met.

\subsection{Environmental Water Provisions}

Environmental water provisions (EWPs) are defined as 'those parts of environmental water requirements that can be met at any given time. This is what can be provided at that time with consideration of existing users' rights, social and economic impacts' (Government of South Australia, 2006). For the MLR, EWPs were determined by identifying a water regime that sustained the environment at an acceptable level of risk (rather than a low level of risk), and balancing this against existing consumptive water demands (figure 4). This section describes the work to identify an environmentally acceptable extraction limit, and not the balancing against consumptive demand.

\subsubsection{Environmental objectives}

The broad environmental objective for the MLR has been set as maintaining self-sustaining populations that are resilient to times of drought. Expert opinion was used to identify the level of ecological condition expected to have an acceptable level of risk of meeting this objective. For example, a native fish target was set for small fish recruitment to be classified as marginal or poor in no more than $30 \%$ of years. The relationships between ecological condition (from environmental monitoring data) and the current state of the EWR metrics at those monitoring sites were then analysed. This assessment found that passing $85 \%$ of the metrics equated to the identified 'acceptable' level of ecological condition for different biotic groups, providing a target for setting an environmentally sustainable extraction level.

\subsubsection{Scenario modelling - towards setting environmentally sustainable extraction limits}

The surface water models were used to generate water use scenarios that involved varying the demand from licensed farm dams, as percentage of dam capacity, at $10 \%$ intervals (Scenario "S3. Variable demand" in figure 4). The flows generated from these scenarios were then compared to flows generated from scenario S2 to identify the percentage of metrics passed at the same 135 testing sites. Analysis of the results indicated that meeting the environmental target of passing $85 \%$ of the metrics (at an acceptable number of sites) could only be achieved with an extraction limit of $<5 \%$ of upstream runoff. While expected to be environmentally sustainable, this extraction limit was considered unlikely to be socially or economically acceptable, driving further work to investigate other options for extraction limits coupled with water-taking rules.

As outlined in section 3.3.1, low flow components have been most strongly affected by current development, and are also thought to be critical for sustaining water-dependent ecosystems by supporting survival over the drier seasons in these ephemeral systems. So, further scenarios were modelled to investigate whether returning or not capturing low flows (at or below a threshold flow rate) at existing licensed dams, licensed 
Savadamuthu et al., Hydro-ecological modelling to establish sustainable extraction limits in unregulated catchments

watercourse diversions and large non-licensed dams would influence the extraction limits (scenario S4 in figure 4).

Analysis of the results indicated that if low flows were returned or not captured by licensed sources and large non-licensed dams, then $25 \%$ of the upstream runoff in the WMLR PWRA, and $15 \%$ of the upstream runoff in the EMLR PWRA, could be extracted at a SWMZ scale, while passing at least $85 \%$ of the metrics at the majority of testing sites and meeting assumed current demand at the majority of testing sites.

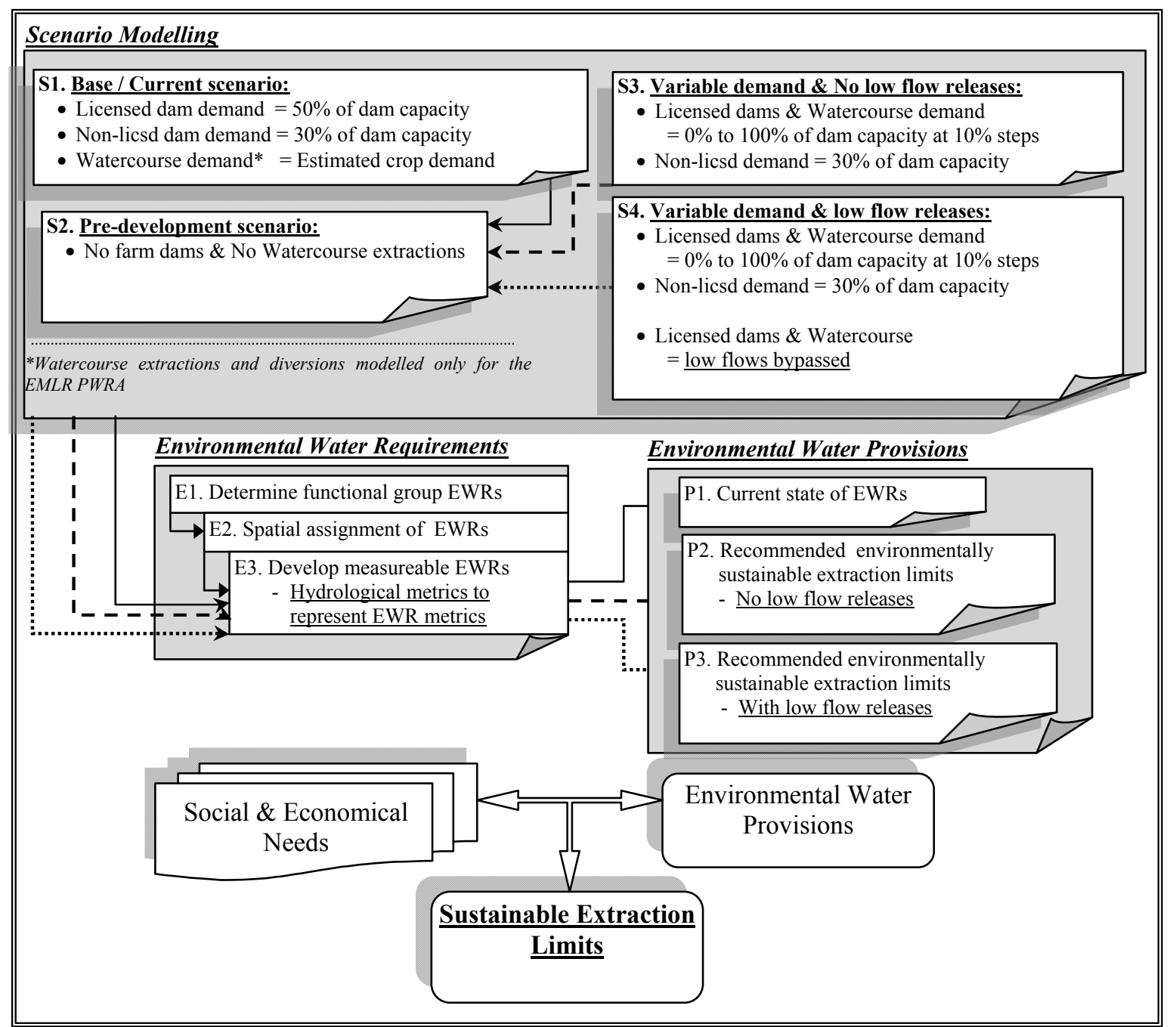

Figure 4. Overview of EWP establishment process

\section{DISCUSSION AND CONCLUSIONS}

Managing water extraction in unregulated catchments sets the challenge of determining water taking rules that can practically apply to thousands of existing private dams and diversions, in order to provide an environmentally sustainable water regime, while supporting social and economic needs for water.

This work found that alteration in when and how water is taken from the system has a significant influence on the size of the extraction limit, while achieving similar or better environmental outcomes compared with managing the volume taken from dams and watercourses alone.

An important outcome of this work is the development of a robust and transparent framework that effectively links ecological outcomes to hydrological process, while considering the needs of other existing water users, using a suite of modelling tools and techniques. The confidence levels of the outcomes of this framework will increase with more data becoming available. The framework can potentially be used in other areas with refinement and inclusion of local outcomes. 
Savadamuthu et al., Hydro-ecological modelling to establish sustainable extraction limits in unregulated catchments

\section{ACKNOWLEDGMENTS}

Funding for this work came from the National Water Commission, the Adelaide and Mount Lofty Ranges Natural Resources Management Board, the South Australian Murray-Darling Basin Natural Resources Management Board, and the former Department for Water, Land and Biodiversity Conservation. Thanks to agency staff who contributed to the project and the EWR expert panel.

\section{REFERENCES}

Alcorn M. R., 2010, Updates to the Capacity of the Surface Water Resource of the Eastern Mount Lofty Ranges: 2010, DFW Technical Note TN2010/04, Department for Water, Adelaide.

Alcorn M. R., 2011, Hydrological Modelling of the Eastern Mount Lofty Ranges: Demand and Low Flow Bypass scenarios, DFW Technical Note 2011/02, Department for Water, Adelaide.

Clark R, Teoh K and Kotz S, 2007, Surface Water Assessment for the Southern Fleurieu Region, DWLBC Report 2009/05, Government of South Australia, through Department of Water, Land and Biodiversity Conservation, Adelaide.

Creswell, D.J., 2010 WaterCRESS User Manual Version: June 2010. Draft Document.

Grayson, RB, Argent, RM, Nathan, RJ, McMahon, TA \& Mein, RG 1996, Hydrological recipes: Estimation techniques in Australian hydrology, Cooperative Research Centre for Catchment Hydrology, Melbourne

Government of South Australia, 2006. State natural resources management plan. Government of South Australia, Adelaide.

Hammer, M, S. Wedderburn and J. van Weenen, 2009. Action plan for South Australian freshwater fishes. Native Fish Australia (SA) Inc and Department for Environment and Heritage, Adelaide.

Poff NL, Allan JD, Bain MB, Karr JR, Prestegaard KL, Richter BD, Sparks RE and Stromberg J. 1997. The natural flow regime: a paradigm for river conservation and restoration. Bioscience, 47: 769-784.

Savadamuthu K \& Teoh K, 2010, Surface Water Resource Capacity Estimates for the Western Mount Lofty Ranges Prescribed Water Resources Area, DFW Technical Note 2010/05, Department for Water, Adelaide.

SA Government. (2009). Managing the Water Resource Impacts of Plantation Forests A Statewide Policy Framework. Adelaide: SA Government.

VanLaarhoven, JM and van der Wielen, M. 2009. Environmental water requirements for the Mount Lofty Ranges prescribed water resources areas. DWLBC Report 2009/29, Department of Water, Land and Biodiversity Conservation \& South Australian Murray-Darling Basin NRM Board, Adelaide.

VanLaarhoven J, 2010, Environmentally sustainable extraction limits for the Western Mount Lofty Ranges Prescribed Water Resources Area, DfW Technical Report 2010/01, Government of South Australia, through Department for Water, Adelaide. 